\title{
A educação para além da escola: considerações sobre o ato de educar à luz de Paulo Freire
}

\section{The education beyond the walls of the school: considerations about the act of educating based on Paulo Freire's thoughts}

\section{La educación más allá de la escuela: consideraciones sobre el acto de educar a la luz de Paulo Freire}

\author{
Keila Miotto $^{1 \mathbb{D}}$; Luís Carlos Negri2 $^{(\mathbb{D})}$; Atílio Catosso Salles ${ }^{3}$ (D)
}

\section{RESUMO}

O presente artigo dirige o seu olhar para algumas práticas educacionais no sentido de buscar reflexões que possam auxiliar na construção de uma educação emancipatória e libertadora (FREIRE, 1987). Levantamos inicialmente algumas considerações para construir um debate que possa promover essa educação para além dos muros da escola e dissertamos sobre o ato de educar e o processo de formação do educador. E, por fim, à luz de Paulo Freire $(1967 ; 1979 ; 1987)$, procuramos tratar dessa educação libertária e dialógica que nos impulsionou a meditar no decorrer dessas páginas e que pretende inquietar, agitar e incomodar a realidade preexistente. Ao contrário da educação bancária, essa nova ação pedagógica proposta por Paulo Freire, quer tirar o aluno de sua zona de conforto, e colocá-lo como parte da construção do conhecimento. E é a partir dessas inquietações que buscamos promover esse momento de diálogo e de reflexões.

Palavras-chave: Práticas pedagógicas; Ambiente escolar; Educação libertária; Educação dialógica.

\begin{abstract}
This article aims to look at some educational practices in order to seek reflections that can help in the construction of an emancipatory and liberating education (FREIRE, 1987). We have initially raised some points to develop a discussion that can promote this education beyond the walls of the school and we have talked about the act of educating and the instruction process of the educator. And finally, based on Paulo Freire's work (1967; 1979; 1987), we attempt to write about this libertarian and dialogical education that has stimulated us to meditate throughout these pages and that intends to unsettle, agitate and disturb the preexisting reality. Unlike banking model of education, this new pedagogical action proposed by Paulo Freire, wants to take students out of their comfort zone, and put them as part of the knowledge building. And it is from these concerns that we seek to promote this dialogue and reflections.
\end{abstract}

Keywords: Pedagogical practices; School environment; Libertarian education; Dialogical education.

\footnotetext{
${ }^{1}$ Doutoranda no Programa de Pós-graduação em Educação, Conhecimento e Sociedade da Universidade Vale do Sapucaí (Univás) e Professora do Instituto Federal de Educação, Ciência e Tecnologia do Sul de Minas Gerais (IFSULDEMINAS), Inconfidentes/MG - Brasil. E-mail: keila.miotto@ifsuldeminas.edu.br.

${ }^{2}$ Doutorando no Programa de Pós-graduação em Educação, Conhecimento e Sociedade da Universidade Vale do Sapucaí (Univás) e Arte-Educador do Instituto Federal de Educação, Ciência e Tecnologia do Sul de Minas Gerais (IFSULDEMINAS), Inconfidentes/MG - Brasil. E-mail: luis.negri@ifsuldeminas.edu.br

${ }^{3}$ Professor do Programa de Pós-graduação em Educação, Conhecimento e Sociedade da Universidade do Vale do Sapucaí (Univás), Pouso Alegre/MG - Brasil. E-mail: atilioc@univas.edu.br
} 


\section{RESUMEN}

Este artículo analiza algunas prácticas educativas para buscar reflexiones que puedan ayudar a la construcción de una educación emancipadora y libertária (FREIRE, 1987). Planteamos inicialmente algunas consideraciones para construir un debate que pueda promover esta educación más allá de los muros de la escuela y disertar sobre el acto de educar y el proceso de formación del educador. Y, finalmente, a la luz de Paulo Freire (1967; 1979; 1987), tratamos de abordar esta educación libertaria y dialógica que nos ha llevado a meditar a lo largo de estas páginas y que pretende inquietar, provocar y desestabilizar la realidad preexistente. A diferencia de la educación bancaria, esta nueva acción pedagógica propuesta por Paulo Freire quiere sacar al alumno de su zona de confort y situarlo como parte de la construcción del conocimiento. Y es a partir de estas inquietaciones que pretendemos promover este momento de diálogo y reflexión.

Palabras clave:

Palabras clave: Prácticas pedagógicas; Entorno escolar; Educación libertária; Educación dialógica.

\section{INTRODUÇÃO}

Caro leitor, achamos importante alertá-lo que as páginas que se seguirão fazem parte de reflexões e pensamentos de dois educadores que há algum tempo, entre erros e acertos, têm buscado ponderar e repensar sobre a sua prática educacional. O intuito desse texto não é, em momento algum, propor um método ou verdades absolutas, pelo contrário, esperamos encontrar interlocutores para que possamos no encontro das ideias, ressignificar o papel do educador. Como numa boa prosa, começamos pelas apresentações: somos professores em uma instituição federal de ensino, o Instituto Federal de Educação, Ciência e Tecnologia do Sul de Minas Gerais, e atuamos no campus Inconfidentes. Ambos temos praticamente o mesmo tempo de trabalho nesta instituição, aproximadamente dez anos, e lecionamos as disciplinas de Arte e Educação Física. Nesse ponto, já nos cabe inserir uma reflexão: as duas disciplinas ocupam um lugar muito particular dentro das instituições escolares. Não seria incomum nos depararmos com ambientes em que essas disciplinas possam ser encaradas como espaço exclusivo de diversão, de entretenimento, de relaxamento, de passatempo. Não negamos que tudo isso possa acontecer no desenvolvimento educacional das mesmas, e muito menos queremos diminuir o valor e a importância da alegria e da diversão dentro do processo educacional. O problema enfrentado é quando o corpo escolar elege essas disciplinas como "menores" por conta disso: alunos veem esse espaço como o lugar da bagunça, passam a desvalorizar os conteúdos apresentados, colegas não encaram os conteúdos trabalhados como importantes e acabam desvalorizando a prática. Além disso, não é incomum que os profissionais de Arte e Educação Física dentro da escola sejam apontados como os organizadores de festas, gincanas, datas comemorativas, murais, etc. Mais uma vez, isso até pode vir a acontecer, contanto que a prática educacional não se resuma a isso e esse posto não seja uma imposição ou venha para diminuir o trabalho dos educadores. Em nosso caso particular, podemos dizer: sim, já nos deparamos com algumas dessas posições. Mas, mais do que transformar esse relato em muro das lamentações, queremos refletir sobre algumas de nossas práticas no sentido de buscar reflexões que possam auxiliar na construção de uma educação emancipatória e libertadora. Para isso, iniciaremos expondo algumas dessas reflexões sobre o ato de educar e o processo de formação do educador. Na sequência, procuraremos construir um debate que possa promover essa educação para além dos muros da escola. E, por fim, à luz de Paulo Freire (1967; 1979; 1987), versaremos sobre essa educação libertária e dialógica que nos impulsiona a meditar sobre essas páginas. 


\section{SER EDUCADOR: O ATO DE EDUCAR E SEU PROCESSO DE FORMAÇÃO}

Pensar a educação nos remete a diferentes leituras e estudos, para assim, compreendermos os apontamentos de diversos autores que se debruçam a pesquisar e apresentar conceitos, na perspectiva do conhecimento e das transformações que ocorrem o tempo todo, diante de uma história que se entrelaça ao contexto e aos valores de uma sociedade. Compreender a educação é conhecer o seu processo histórico diante do contexto social em que ela se encontra. Dessa forma, podemos pensar que, à medida que a sociedade busca o conhecimento, precisamos questionar se a educação que estamos ofertando vai de encontro ao momento em que estamos fazendo a educação.

As constantes mudanças ocorridas na sociedade, o avanço da tecnologia, da ciência, o acesso à informação, a política, a economia, têm se relacionado diretamente ao contexto escolar e influenciam as concepções da escola, do professor e do aluno. E é por meio de tantas mudanças, que a educação se faz fundamental em suas ações, no ensino, no papel do professor, nas práticas pedagógicas, no currículo e na aprendizagem. Assim, a escola precisa se democratizar e se abrir à sociedade, e o professor assumir o seu papel no compromisso social diante de tantas transformações e exigências. O professor precisa repensar a sua prática mediando e possibilitando a participação do aluno na construção do conhecimento, no intuito de formar cidadãos críticos, atuantes como agentes sociais, participativos e transformadores no processo de construção do ensino e da aprendizagem.

[...] educador é aquele que, tendo adquirido o nível de cultura necessário para o desempenho de sua atividade, dá direção ao ensino e aprendizagem. Ele assume o papel de mediador entre a cultura elaborada, acumulada e em processo de acumulação da humanidade (LUCKESI, 1993, p. 115).

Tanto a escola em suas práticas de educação, como o professor em sua prática pedagógica e o aluno em sua aprendizagem são instrumentos responsáveis pelo processo de construção do conhecimento. Cabe ao professor ser o organizador, o estimulador e o orientador na troca de diálogo e de compartilhamento de saberes, para que o processo de ensino e aprendizagem aconteça. Por isso, é necessário conhecer e refletir sobre a sua prática pedagógica.

A formação não se constrói por acumulação (de cursos, de conhecimentos ou de técnicas), mas sim através de um trabalho de reflexividade crítica sobre as práticas e de (re) construção permanente de uma identidade pessoal" (NÓVOA, 1992, p. 25).

Considera-se a Educação como, "o ato de educar. Ação ou efeito de educar, de aperfeiçoar as capacidades intelectuais e morais de alguém" (DICIO, 2021).

A educação abrange os processos formativos que se desenvolvem na vida familiar, na convivência humana, no trabalho, nas instituições de ensino e pesquisa, nos movimentos sociais e organizações da sociedade civil e nas manifestações culturais. A educação escolar, que se desenvolve, predominantemente, por meio do ensino, em instituições próprias. A educação escolar deverá vincular-se ao mundo do trabalho e à prática social. (BRASIL, 2020, p. 8).

A educação vem se transformando ao longo dos anos e acontece fortemente ligada ao contexto político, econômico e cultural da sociedade. Como nos diz Pinto, "a educação é o processo pelo qual a sociedade forma seus membros à sua imagem e em função de seus interesses" (1987, p. 29), 
entendemos com isso, que a educação sempre será um desafio, quer ela esteja nos moldes das instituições formais, quer ela esteja além dos muros da escola.

Por tratar-se essencialmente de um ato político, a educação torna-se um lugar de contradições e debates. E é sempre bom salientar que essas contradições são importantes no processo educacional do ser humano, pois são elas que fazem emergir questionamentos, inquietações e o desejo por buscar conhecer mais.

\begin{abstract}
Vale lembrar que, historicamente, a educação sempre consistiu um espaço de contradições. Ao mesmo tempo em que se prestou a ratificar uma ordem estabelecida, também alimentou sonhos de mudança e, sob certas circunstâncias, até é capaz de transformar sujeitos e, consequentemente, a própria sociedade. A questão é que as contradições permeiam os sujeitos que estão envolvidos com esse pensar, ou seja, não existe um lugar "seguro", de onde podemos nos instalar e olhar o mundo com clareza, definindo a priori o ideal tanto de sujeitos que queremos construir como o de sociedade que almejamos. (MOURA; ZUCCHETTI, 2010, p. 638).
\end{abstract}

Quando temas e acontecimentos que cercam a comunidade escolar, como qualidade de vida, direitos humanos, meio ambiente, necessidades especiais, gênero, etnia, nacionalidade, questões de crença e fé, a violência, as drogas, a falta de segurança, os problemas com as políticas públicas, são levados para dentro da escola, fundem-se esses dois espaços chamados de formais e não-formais, e é nesse encontro, que extrapola as dimensões físicas dos muros que separam esses dois ambientes, que se efetivam os espaços de formação e de educação.

É preciso destacar que, muitas vezes, a educação assume um caráter segregador: divide quando deveria unir. Isso porque, como já abordamos anteriormente, a educação encontra-se aliada ao seu percurso histórico, e assim, vê-se atrelada, atualmente, à lógica capitalista e mercantilista. Nesse sentido, o cidadão torna-se consumidor e o conhecimento vê-se aliado à mão de obra e à oferta de empregos. Vista por esse ângulo, a educação limita-se à função de mero suporte, ao invés de pretender-se transformadora. "Sinalizo a abertura para a transformação, para o vir-a-ser. Ensinar não necessariamente configura-se como transmissão e aprender não necessariamente configura-se como recepção" (SÁ, 2011, p. 90). Tomando como elemento de reflexão as palavras de Sá, percebemos que a educação não é uma esfera exata, pronta, estática, imóvel e acabada, ao contrário, deve ser um lugar em constante transformação. Nesse sentido, complementa Orlandi (2016, p. 71): "o conhecimento precisa da incompletude, do inacabamento, da errância dos sujeitos e dos sentidos, de sua inexatidão".

Se a educação não pode ser desassociada da sociedade, carecemos lembrar constantemente que essa mesma sociedade é formada de sujeitos plurais em suas crenças e manifestações de fé, em suas cores e sabores, em seus olhares, na construção, fruição e apreciação da arte, na sua língua e nas expressões e formas de comunicar, enfim, na construção do seu ser-no-mundo. E é esse mesmo ser que adentra a porta das salas de aula. Ele não desvincula-se de suas bagagens sociais e culturais ao ingressar no espaço escolar. Por isso, um dos maiores equívocos que nós, educadores, podemos cometer é querer enxergar os nossos alunos como seres uniformes, prontos e acabados. Optamos por segregá-los em salas fechadas, em números, em séries, em fileiras de carteiras, em filas, e muitas vezes, nos esquecemos de abrir espaço para a dúvida, para a interrogação, para a invenção, para a descoberta, que juntas geram o conhecimento. 


\section{REFLEXões SOBRE A PRÁtICA PEDAGógICA: A ESCOLA PARA ALÉM DE SEUS MUROS}

Diferentes práticas pedagógicas acontecem na organização em atender expectativas educacionais como demanda em uma comunidade escolar, ou seja, acontecem de diferentes maneiras e formas, de acordo com o ambiente em que o professor se encontra. Nesse sentido, a sua prática está relacionada a diferentes intervenções, podendo estas advir de negociações, deliberações ou até imposições. O professor tem o papel fundamental na sua prática, sendo ele o responsável pela escolha dos conteúdos que irá ministrar e apresentar em sua aula e que será de extrema importância para a formação do aluno. (FRANCO, 2012).

Quando se fala em prática pedagógica, refere-se a algo além da prática didática, envolvendo: as circunstâncias da formação, os espaços-tempos escolares, as opções da organização do trabalho docente, as parcerias e expectativas do docente. Ou seja, na prática docente estão presentes não só as técnicas didáticas utilizadas, mas, também, as perspectivas e expectativas profissionais, além dos processos de formação e dos impactos sociais e culturais do espaço ensinante, entre outros aspectos que conferem uma enorme complexidade a este momento da docência (FRANCO, 2012, p. 542).

A prática da educação não se limita ao espaço físico da sala de aula, dos muros escolares, e nem exclusivamente na figura do professor, podendo se fazer a todos os momentos, de diferentes formas, por meio das trocas de conhecimentos, compartilhamento de experiências, de saberes. Assim, a educação não acontece somente dentro da escola, ela se faz em diferentes lugares, de diferentes formas, ou seja, na família, na comunidade, no bairro, no clube, e sua aprendizagem acontece no processo de socialização, com a interação que ocorre na busca do conhecimento.

Para que isso aconteça é necessário que a escola, o professor, os alunos e a comunidade, entendam qual o seu papel diante da educação. É preciso que todos tenham consciência da importância de compartilhar o conhecimento, percebendo os diferentes espaços e pessoas, para que tudo tenha significado, constituindo assim, o mais importante sentido da educação. Em muitas das vezes, os alunos nos levam a pensar e repensar as práticas pedagógicas que estamos levando à escola. Nós, professores, em alguns momentos somos autoritários na escolha de nossas práticas, reproduzindo modelos do neoliberalismo como, produtivismo, elitismo, transformando o ensino em valor de troca. Para tanto, faz-se urgente que entendamos as mudanças constantes que ocorrem na sociedade, para que possamos questionar nossas escolhas ao que ensinar e ao que aprender.

Somos todos aprendizes de nossas práticas em mudança, visto que a aprendizagem faz parte de nossas relações sociais. A criança pode aprender relacionando-se em diferentes espaços: no campinho de futebol do seu bairro, nas brincadeiras com seus amigos, na igreja, no pomar ao saborear as frutas e perceber a passagem das estações, no trabalho árduo e diário de seus familiares e na sala de aula. Assim, torna-se fundamental destacar que o ambiente escolar não é o único e exclusivo lugar da aprendizagem, como muitos ainda insistem em querer enxergar. A educação vai muito além dos muros da escola. Todos os ambientes estão nos ensinando constantemente. $E$ somos todos seres ensinantes e aprendentes.

Fala-se muito sobre a escola para além de seus muros. É preciso compreender que esses muros são físicos, mas também metafóricos. É importante derrubar os muros físicos e fazer com que a escola se abra para a comunidade. Os muros, muitas vezes, são estruturas que justificam-se por conta da segurança, mas em inúmeras experiências exitosas da educação, percebemos que essa segurança se dá muito mais quando a escola rompe os seus muros e divide as responsabilidades com a comunidade 
que a circunda. Mas, esses muros são também metafóricos, ou seja, símbolos de uma escola que se fecha para o outro. Podemos perceber, por exemplo, muitas vezes a sala dos professores como a sala das reclamações, a sala dos preconceitos. Esse espaço, que deveria ser pedagógico e de construção das vivências escolares torna-se, por vezes, o "muro das lamentações" sobre a vida dos alunos e do ambiente escolar. Assim, a escola vive na prática um ambiente de repressão, quando deveria ser um ambiente de criação e de libertação.

Apesar do avanço veloz das redes de vigilância eletrônica que se infiltram pelos muros das escolas atuais, fazendo circular imagens e informações em tempo real, ainda é costume proibir os alunos de entrar nos edifícios com suas próprias câmeras e demais dispositivos característicos da sociedade de controle, como celulares, computadores ou tablets. Ou, pelo menos, procura-se evitar isso mediante uma balbuciante promulgação de leis, decretos e normas, ou se dosa seu uso em cada caso por meio de negociações internas mais ou menos enfáticas; ou ainda, o que é cada vez mais habitual em virtude do conflito crescente: fiscaliza-se esse uso pedagogicamente por meio de programas oficiais de informatização das aulas. (SIBILIA, 2012, p. 173).

Que escola é essa que se assemelha a ambientes disciplinares? Critica-se tanto o uso do celular dentro da sala de aula, e de repente, por conta de uma inesperada pandemia, este torna-se o principal instrumento pedagógico de ensino nas mãos de alunos e professores. Será que não precisamos repensar as nossas práticas? Que tipos de modos de ser e estar no mundo são criados nesse ambiente que prega liberdade, mas vive aprisionamento? Ao voltarmo-nos para reflexões como essas é que podemos afirmar: devemos buscar vivenciar uma escola em redes e não uma escola com muros.

Por vivermos em um mundo globalizado, todas as ações giram em torno do capitalismo. Nesse sentido, inclusive a escola acaba tendo que se adaptar às condições do mercado. Diante das transformações e exigências do mercado, o educador se encontra num lugar de propositor dessa educação libertadora, ou seja, tem a missão de formar cidadãos críticos e pensantes diante de uma realidade cruel e massacrante que só preocupa-se com a força do capital.

Nesse sentido, o professor deve usar seu processo pedagógico para que o aluno saiba o porquê de estar aprendendo, e desse modo, a aula se transforma em produção de saberes. O professor assume, portanto, o papel de organizador e promotor do processo educacional. É preciso pensar a educação como um processo dos sentidos, um processo em constante construção e desconstrução, um processo de busca incessante.

Mas, é indispensável que saibamos que esse modo inovador de pensar a educação pode não ser bem-visto ou bem quisto dentro das instituições escolares, visto que certamente iremos esbarrar em leis e práticas antiquadas e tradicionais, e em gestores e colegas de trabalho dispostos a não abrir mão dessas práticas que vêm sendo aplicadas por anos a fio. Aproveito para lançar mão de um evento que aconteceu durante as minhas práticas como arte-educador e que pode exemplificar perfeitamente a reflexão anterior. Ao compartilhar as minhas práticas pedagógicas voltadas para um aluno portador de necessidades específicas especiais em uma reunião pedagógica, lembro de ter sido questionado por um colega sobre o porquê do aluno ter conquistado a nota apresentada. Nas falas do colega professor, a nota só poderia ter sido "inventada", não poderia refletir o real aprendizado do mesmo, uma vez que na disciplina lecionada por ele o aluno nunca conseguia atingir um conceito positivo. Ao procurar responder tal questionamento (para não dizer acusação), tentei alertar todo o grupo para a necessidade de uma avaliação que fosse feita de forma individualizada, olhando para as especificidades de cada aluno. Afinal, não é exatamente disso que deveria tratar-se a inclusão? E não falava somente da avaliação diferenciada e específica que deveria ser aplicada àquele aluno, em 
particular, mas de todas as avaliações aplicadas a todos os alunos. Até que ponto a nota, um número e conceito supervalorizado pelo colega que me questionou, remete ao sucesso ou fracasso do aluno? Estamos levando em consideração o aprendizado real de nossos alunos, ou estamos buscando um ranking de colocação entre os mesmos? É preciso ter claro que a nota apresentada por mim na ocasião relatada, refletia o resultado de encontros, discussões, superação de dificuldades, e um aprendizado real e significativo na vida de um aluno que por muito tempo viu-se alheio ao processo educacional e excluído das atividades de ensino-aprendizagem. Tudo isso nos faz abrir os olhos para a urgência de buscarmos uma educação que fuja daquela que pretende uniformizar os discentes, encará-los de forma homogênea. Olhemos à nossa volta: somos seres diversos, heterogêneos, e não podemos mais considerar uma educação que não aproveite e mergulhe nessas diferenças entre os seres humanos.

Se a estrutura atual da escola exclui, isso mostra que ela precisa ser repensada. Se continuarmos arremessando sobre os alunos que chegam à escola toda essa carga de estigmas e estereótipos, estaremos cada vez mais dificultando o seu aprendizado, incapacitando o seu percurso e o seu desenvolvimento. Devemos olhar para o nosso aluno como um ser único e diverso, como somos todos nós, e não medi-lo a partir de réguas de comparação com o outro, caso contrário, estaremos novamente excluindo sob o falso codinome da inclusão. $E$ a inclusão do outro não precisa e nem deve limitar-se exclusivamente ao cunho pedagógico, mas é preciso dar garantias de que ele será inserido também na sociedade, trata-se de mostrar o seu lugar no mundo.

A desvalorização das disciplinas Arte e Educação Física no ambiente escolar nos remete a pensar como a educação ainda não se encontra de forma igualitária. Duas disciplinas componentes obrigatórias do currículo que lutam o tempo todo por seu espaço. Como educadora da disciplina Educação Física, nos corredores escolares me deparo frequentemente com a seguinte fala: "Já vai jogar bola com os alunos?". Como se a disciplina se resumisse a isso, "jogar bola". Inúmeras falas, acontecem o tempo todo, diminuindo uma disciplina tão importante, que não se faz somente dentro dos muros escolares, mas que se faz diariamente, na busca por qualidade de vida e saúde, entre muitos outros benefícios, para além do físico e do mental, agregando valores na formação do cidadão para o mundo. Confesso que, em inúmeros momentos escolares, em reuniões e encontros, me senti fora do contexto, me deparando com atos demonstrando preconceito para com alunos que possuem habilidades físicas esportivas. Por diversas vezes, presenciei as seguintes falas de colegas professores perante toda a comunidade escolar: "esse aluno só quer jogar bola?", "esse aluno veio se formar para o esporte?", "esse aluno, quando sair da escola, vai ser professor de Educação Física?". São falas que, erroneamente, demonstram que o papel da Educação Física na escola não se encontra à altura das outras disciplinas.

Por essa e inúmeras outras ocasiões em que nos deparamos com questionamentos de colegas à nossa prática educacional, pelas incontáveis vezes em que presenciamos profissionais da educação destilando uma infinidade de estereótipos e preconceitos dentro do ambiente escolar, chegamos a sugerir certa vez, em um ímpeto de frustração e indignação: será que teremos que mudar o nome da sala dos professores para sala dos preconceitos? Até quando teremos que ouvir em reuniões que teriam como objetivo refletir sobre o aprendizado dos alunos, falas que pretendem justificar o nãoaprendizado a partir das condições sociais dos mesmos, de seu entorno familiar e cultural, de sua aparência, de sua orientação sexual, de seus relacionamentos pessoais? Pode parecer absurdo, mas já ouvimos em ambientes como esse que o aluno $x$ não conseguia aprender porque estava de namoradinho novo, que a aluna y não tinha futuro por conta do seu ambiente familiar, que os alunos 
a, b e c teriam que ser separados para que passassem a se interessar mais pelos estudos e menos por funk ou outras bobagens que só querem corrompê-los, que o processo de cuidado com a saúde corporal do aluno h era condição desfavorável ao seu aprendizado em determinada disciplina. Em um ambiente educacional que tem se aberto cada vez mais para as diferenças, tem se tornado plural e diverso, nos deparamos com inúmeros profissionais que resistem a essas mudanças, e querem mantê-lo cada vez mais homogêneo e disciplinado. Em suma, destila-se uma infinidade de estereótipos e preconceitos, em um ambiente que deveria ser o da liberdade e o da criação. Perguntamos então: Estamos preparados para dialogar com esses alunos? Estamos dispostos a repensar a nossa prática educacional?

Diante disso, podemos concluir que a prática do professor relaciona-se a diferentes contextos de formação o que pode interferir diretamente na sua prática em sala de aula. Assim, ressaltamos a importância deste em conhecer o seu ambiente de trabalho e seus alunos, para que o desafio do processo de ensinar e aprender sejam compartilhados em sua prática e sejam pautados na formação e na aprendizagem, proporcionando espaço de trocas educativas entre o professor e seus alunos.

\section{POR UMA EDUCAÇÃo LIBERTÁRIA E DIALÓGICA: REVERBERAÇÕES SOBRE O ATO DE EDUCAR À LUZ DE PAULO FREIRE}

Paulo Freire, exímio educador e pensador da educação, nos aponta através de seus inúmeros escritos as diretrizes para a construção de uma prática pedagógica libertária e dialógica. Para isso, uma das primeiras ações deve ser a busca por conscientizar o aluno, ou seja, fazê-lo olhar para si mesmo e para sua condição de ser oprimido, e por meio dessa identificação criar nele a condição de ser pensante que possa refletir criticamente sobre a sua realidade. Assim, ao propor meios para que o discente volte o seu olhar para a sua realidade e para sua condição, reflita sobre a mesma, ele terá elementos para alcançar a sua libertação enquanto sujeito vivente.

Freire (1967) nos remete a pensar em que prática de ensino estamos levando aos nossos educandos: a prática da dominação ou a prática da liberdade? Diante do mundo globalizado e neoliberal, em que pensamentos e ações se voltam ao mercado capitalista dominador, devemos repensar quais as estratégias que a educação tem buscado como forma de libertar a sociedade da opressão. Uma educação dialógica, transformadora e emancipatória é fundamental para que ocorra a conscientização da gestão escolar, do corpo docente, dos alunos e da comunidade.

Não é possível um compromisso verdadeiro com a realidade, e com os homens concretos que nela e com ela estão, se desta realidade e destes homens se tem uma consciência ingênua. Não é possível um compromisso autêntico se, àquele que se julga comprometido, a realidade se apresenta como algo dado, estático e imutável. Se este olha e percebe a realidade enclausurada em departamentos estanques (FREIRE, 1979, p. 10).

Não construiremos uma formação humana se não dermos possibilidade ao questionamento, acreditando que a educação que se faz somente nas carteiras da escola é suficiente para a vida. É preciso proporcionar a professores e alunos a compreensão de que a educação precisa ser transformadora, propondo oportunidades a todos no processo de aprendizagem, com autonomia e realização.

Historicamente, ao voltarmos nossos olhos para o ambiente escolar, é comum que encontremos práticas pedagógicas que esperam encontrar alunos dóceis, receptivos e prontos para serem 
preenchidos por um conhecimento que vem sempre de forma unilateral, ou seja, do professor para o aluno, de cima para baixo, diminuindo, portanto, a posição do aluno e colocando-o na condição de oprimido. Não é incomum nos depararmos com metáforas no ambiente escolar que comprovam tal visão, ao colocar o aluno como "folhas em branco" que devem ser preenchidas pelo professor, "sementinhas" que precisam ser regadas pelo professor para que germinem, floresçam e dêem frutos. Essas são características próprias de uma educação mais conservadora, que Paulo Freire (1987) nomeia de educação bancária. Interessa a esse tipo de educação manter os alunos acomodados, imóveis e alienados à realidade existente.

Anteriormente, ao refletirmos sobre a prática pedagógica, inserimos algumas experiências com as quais nos deparamos em nosso percurso enquanto professores de Arte e Educação Física, que vão de encontro a essa educação enrijecida que Paulo Freire critica em seus escritos: a busca constante pela homogeneização do corpo discente, com a inserção dos mesmos em um ranking de notas e conceitos, que mais do que medir o seu real aprendizado, busca incitar a comparação e a competição entre os mesmos; a crítica a quaisquer práticas educacionais que venham fugir do velho arcabouço tradicional da sala de aula; os olhares tortos para o interesse de qualquer aluno pelo meio artístico ou corporal, como se eles só o pudessem fazê-lo como forma de distração e lazer, e devessem dedicação exclusiva somente àquelas disciplinas que integram o "hall das mais importantes", relegando à Arte e Educação Física o cunho de "disciplinas menores".

Paulo Freire defende uma educação libertária, que vai inquietar, agitar e incomodar a realidade preexistente. Ao contrário da educação bancária, essa nova ação pedagógica proposta por ele, quer tirar o aluno de sua zona de conforto, e colocá-lo como parte da construção do conhecimento.

Em verdade, não seria possível à educação problematizadora, que rompe com os esquemas verticais característicos da educação bancária, realizar-se como prática de liberdade, sem superar a contradição entre o educador e os educandos. Como também não lhe seria possível fazê-lo fora do diálogo. (...) Já agora ninguém educa ninguém, como tampouco ninguém se educa a si mesmo: os homens se educam em comunhão, mediatizados pelo mundo. (FREIRE, 1987, p. 44).

Para se construir uma prática de liberdade, é importante que a educação seja dialógica, ou seja, ela precisa ouvir o outro, socializar ideias e pensamentos, compartilhar histórias e vivências, para que, assim, a educação se encontre transformadora, libertadora e emancipatória. É necessário que o professor conscientize e reflita sobre a sua prática para assim fazer com que ela se transforme. 0 papel do educador se encontra no compromisso social, diante de tantas exigências. Repensar a sua prática, a fim de formar cidadãos críticos e capazes de se tornarem agentes sociais atuantes, participativos e transformadores. Dialogar, promover discussões, impulsionar o pensamento, permitir o olhar ao mundo que está a sua volta, percebendo que a sociedade se encontra em contínua transformação, sendo a educação aliada ao processo da humanização, para que todos tenham a mesma formação e oportunidade enquanto sujeitos da sua própria história.

Nas páginas anteriores, ao apontar algumas reflexões sobre as nossas práticas pedagógicas, relatamos desafios enfrentados dentro do ambiente escolar ao tentar propor procedimentos educativos que quebrassem com um ensino mais tradicional e engessado. Vimos que tais ações podem despertar olhares de reprovação e de repressão, e podem disparar até atos de preconceito e negação. Mas, é importante deixar registrado que mesmo enfrentando forças contrárias, essas práticas adotadas por nós geraram força motriz e vêm surtindo inúmeros efeitos positivos e que vão de encontro às reflexões que buscamos levantar nesse breve estudo. No intuito de exemplificar, 
dividiremos como vocês, caros leitores, dois breves relatos relacionados às nossas áreas de atuação para que possamos finalizar essas reflexões com aspectos de otimismo e esperança.

Dentro da área de arte e cultura em nosso campus, além dos trabalhos em sala de aula, conseguimos desencadear ao longo dos anos inúmeras ações, instaurando um ambiente chamado Casa das Artes, que tem como intuito fomentar e apoiar ações artístico-culturais que possam ser oferecidas à comunidade interna e externa ao campus, em projetos de caráter extensionista, porém ligados ao ensino e à pesquisa. Um desses projetos é o Grupo de Teatro Arte Federal que tem como intuito promover experimentações cênicas, e dentro dele, temos desenvolvido diversos processos de criação em que o caráter dialógico e a educação libertária estavam dentre as bandeiras principais a serem levantadas. Ao longo dos processos educacionais instaurados percebemos o despertar de uma urgência por fomentar a voz conquistada por meio do teatro e também a escuta do outro e de suas necessidades. Para citar alguns desses processos, tivemos "Causos, Café e Canções" (2014), criado integralmente pelo grupo e baseado nas histórias colhidas no meio em que viviam os integrantes do processo, "A Casa dos Seres Invisíveis" (2016) que debruçou-se sobre o tema da loucura e procurou trazer à luz esses seres invisíveis socialmente e "Na Terra dos Homens de Bem" (2018) que procurou despertar nos alunos um olhar crítico para os acontecimentos recentes e o constante ataque aos direitos humanos e aos seres tidos como diferentes. Por meio desses processos pudemos perceber nos membros do projeto a abertura para temas novos e de relevância, muitas vezes ignorados, mas que geraram sentimentos como a valorização da cultura popular do seu entorno, a importância por ouvir a voz do outro, a tentativa e a busca da luta pelo não-silenciamento, a valorização dos seres, a luta por direitos e a busca por mais igualdade social.

Como professora de Educação Física sempre tive o incômodo em ver alunos não participando das aulas, e por esse fato, com muita reflexão à minha prática e no diálogo com rodas de conversas e trocas de experiências, diferentes temas de aulas foram surgindo com o objetivo de que todos os alunos participassem e vivenciassem as propostas da disciplina. Dentre essas muitas atividades, muitas delas surgidas em conversas, trago nessas linhas algumas experiências que me fazem acreditar que caminhamos juntos na educação. Os alunos propuseram ações que fizessem sentido às suas vidas cotidianas e diante disso, propostas de projetos foram surgindo em pensamentos comuns, a fim de que a construção do conhecimento não ficasse somente na "sala de aula". Para isso, projetos de extensão têm surgido com o intuito de "derrubar os muros" para assim a comunidade fazer parte da escola. Entre tantos exemplos que vão além do esporte, temos projetos como o "IF Esporte para todos", com esporte recreacional, sem caráter competitivo; o projeto "Conexões Saudáveis", com dicas de diferentes profissionais da saúde; o "IFeducativo", com atividades físicas no intuito de proporcionar uma vida ativa a todos; a "Semana de qualidade de vida e saúde", com palestras de nutrição, fisioterapia, terapia ocupacional, com o intuito de melhorar a qualidade de relacionamento, qualidade na alimentação e qualidade no trabalho.

Se a escola não se atentar às transformações diárias que acontecem na sociedade, os professores não refletirem sobre a sua própria prática e a comunidade não dialogar no processo de construção do ensino e da aprendizagem, a educação se fará como mera reprodução da sua própria história, ou seja, continuará replicando uma educação conservadora, crítica e oprimida. Para se fazer uma educação transformadora, é necessário que toda a comunidade escolar se envolva na reestruturação do ensino e nos objetivos da aprendizagem, rompendo barreiras históricas, políticas e sociais, para se fazer novos espaços educativos, em que todos tenham igualdade de condições e oportunidades. 
Ressaltamos que a escola não é o único instrumento no processo de humanização e transformação do ser humano e da sociedade. Mas, ela torna-se importante quando luta pelo conhecimento universal, produzido pela humanidade, que dialoga, que socializa, que recria, e que se faz solidária e justa. Nesse sentido, Paulo Freire aponta que ao mudarmos, mudamos o mundo, e isso nos leva a refletir sobre a nossa prática por meio dos estudos, das ações e da ressignificação, para assim, podermos contribuir para uma transformação social mais justa para todos.

Entre inúmeros erros e acertos, podemos afirmar que em nosso processo contínuo de ser-educadores, temos buscado práticas que anseiam por uma educação mais libertária e dialógica. Alguns dos desafios enfrentados no processo puderam ser evidenciados ao longo dessas explanações, assim como algumas das práticas pedagógicas das quais lançamos mão. Mas, é imprescindível ressaltar, por fim, à luz das reflexões de Paulo Freire, que o caminho percorrido não se faz de forma retilínea e direta. Tanto para educadores-educandos quanto para educandos-educadores o caminho se trilha através do encontro, da comunhão, do diálogo e da troca de saberes.

\section{REFERÊNCIAS}

BRASIL. Lei de Diretrizes e Bases da Educação Nacional (LDB). Disponível em: https://www2.senado.gov.br/bdsf/handle/id/572694 Acesso em: 22 de mai 2021.

DICIO. Dicionário Online de Português. Disponível em: https://www.dicio.com.br/educacao/. Acesso em: 11 mai 2021.

FRANCO, Maria Amélia Santoro. Práticas pedagógicas nas múltiplas redes educativas. In: LIBÂNEO, José Carlos; ALVES, Nilda. Temas de Pedagogia: diálogos entre didática e currículo. São Paulo: Cortez, p. $169-188,2012$.

FREIRE. Paulo. Educação como prática da liberdade. Rio de Janeiro: Paz e Terra, 1967. . Educação e mudança. 12 ed. Rio de Janeiro: Paz e Terra, 1979. Pedagogia do oprimido. 17 ed. Rio de Janeiro: Paz e Terra, 1987.

LUCKESI, Cipriano Carlos. Filosofia da educação. 21 ed. São Paulo: Cortez, 1993.

MOURA, Eliana Perez Gonçalves de; ZUCCHETTI, Dinora Tereza. Educação além da escola: acolhida a outros saberes. Cadernos de Pesquisa, Fundação Carlos Chagas, v. 40, n. 140, p. 629-648, maio/ago 2010.

NÓVOA, António. (Org.). Vidas de Professores. 2 ed. Porto, Portugal: Porto Editora, 1992.

ORLANDI, Eni Puccinelli. Educação e sociedade: o discurso pedagógico entre o conhecimento e a formação. Revista Latino-Americana de Estudos do Discurso, Universidade de Brasília, Universidad Católica de Chile, v. 16, n. 2, p. 68-80, ago-2016.

PINTO, Álvaro Vieira. Sete lições sobre educação de adultos. 5 ed. São Paulo: Cortez, 1987.

SÁ, Érica Aparecida de. Tornar-se Educador. In: CLARETO, Sônia Maria; ROTONDO, Margareth A. Sacramento; VEIGA, Ana Lygia Vieira Schil da (Orgs.). Entre composições: formação, corpo e educação. Juiz de Fora: Ed. UFJF, 2011. 
SIBILIA, Paula. Redes ou paredes: a escola em tempos de dispersão. Rio de Janeiro: Contraponto, 2012.

Submissão: 18/10/2021

Aceito: 07/12/2021 